\title{
PERLAWANAN KESULTANAN MELAYU JAMBI TERHADAP KOLONIAL BELANDA: KASUS SULTAN MUHAMMAD FACHRUDDIN (1833-1844 M) DAN SULTAN THAHA SAIFUDDIN (1855-1904 M)
}

\author{
Ona Yulita \\ UINImam Banjol,onayulita@rocketmail.com \\ Doni Nofra \\ LAIN Bukittinggi, doninofra25@gmail.com
}

\begin{abstract}
Disclosure about the formation and development of the Islamic empire in the archipelago, including the underdeveloped field of study. Though the history of the empire in the archipelago is very much to be discussed, both large and small that affect the form of local Islamic traditions and culture. Writing about the sultanate of the archipelago is very little, this is because of limited resources such as local texts, tambo, chronicles, saga, genealogies and so forth. Moreover, an empire in the archipelago that is not too large, will increasingly difficult to express its history and development. Therefore, the study of the Islamic Sultanate in Jambi is a rather neglected study. In fact, according to Azyumardi Azra Jambi is one of the regions in the archipelago that was first visited by Muslim traders from Arabia. The history of the empire in the archipelago is full of tension and conflict, this has made it easier for Western Imperialism to colonize the archipelago. This is not because of its enormous military strength but because of the internal weaknesses of the sultanates in the archipelago who often wage war, intrigue, and try to master each other. One by one the sultanates in the archipelago were controlled, and Western Imperialism took huge profits through the trade routes controlled by the kingdom. The sultanate who was too violent in giving resistance was threatened to be abolished by Western Imperialism.
\end{abstract}

Keywords: Perlawanan, Kesultanan Melayu, Kolonial Belanda, Sultan Muhammad Fachruddin, Sultan Thaha Saifuddin.

\begin{abstract}
Abstrak
Pengungkapan tentang pembentukan dan perkembangan kesultanan Islam di Nusantara termasuk bidang kajian yang terbelakang. Padahal sejarah kesultanan di Nusantara sangat banyak untuk. dibahas, baik besar maupun kecil yang mempengarubi bentuk tradisi dan budaya Islam lokal. Penulisan tentang kesultanan Nusantara sangat sedikit sekali, hal ini dikarenakan sumber-sumber yang terbatas seperti naskah-naskah lokal, tambo, babad, bikayat, silsilah-silsilab dan lain sebagainya. Terlebih lagi suatu kesultanan di Nusantara yang tidak terlalu besar, akan semakin sulit mengungkapkan sejarah dan perkembangannya. Oleh sebab itu, studi tentang Kesultanan Islam di Jambi termasuk. kajian yang agak terabaikan. Padabal, menurut Asyumardi Azra Jambi termasuk salah satu wilayah di kepulauan Nusantara yang paling awal disinggabi oleh pedagang muslim dari Arab. Sejarah kesultanan di Nusantara penuh dengan ketegangan dan konflik, hal ini menyebabkan mudahnya Imperialisme Barat menjajah Nusantara. Hal ini bukan karena kekuatan militernya yang sangat besar tetapi karena kelemahan internal kesultanan di Nusantara yang sering berperang, intrik, dan berusaha saling menguasai. Satu-persatu kesultanan di Nusantara dikuasai, dan Imperialisme Barat mengambil keuntungan besar melalui jalur perdagangan yang dikuasai oleh kerajaan.
\end{abstract}




\section{Kesultanan yang terlalu keras memberikan perlawanan diancam akan dihapuskan oleh Imperialisme Barat.}

Kata Kunci: Perlawanan, Kesultanan Melayu, Kolonial Belanda, Sultan Muhammad Fachruddin, Sultan Thaha Saifuddin.

\section{PENDAHULUAN}

Penulisan sejarah Islam di Nusantara, seringkali direduksi menjadi sekedar sejarah Islam di Indonesia yang keberadaan dan perkembangannya bukan dipandang sebagai Sejarah Indonesia itu sendiri. ${ }^{1}$ Karel Steenbrink mengeluh tentang model penulisan Sejarah Islam Indonesia yang bersifat fragmentasi dan gerakan-gerakan Islam modernis yang muncul pada abad ke-20 M, sehingga sulit membentuk a grand theory yang menceritakan secara kronologis tentang sejarah Islam dalam konteks Nusantara. ${ }^{2}$ Pengungkapan tentang pembentukan dan perkembangan kesultanan Islam di Nusantara termasuk bidang kajian yang terbelakang. Padahal sejarah kesultanan di Nusantara sangat banyak untuk dibahas, baik besar maupun kecil yang mempengaruhi bentuk tradisi dan budaya Islam lokal.

Penulisan tentang kesultanan Nusantara sangat sedikit sekali, hal ini dikarenakan sumbersumber yang terbatas seperti naskah-naskah lokal, tambo, babad, hikayat, silsilah-silsilah dan lain sebagainya. Terlebih lagi suatu kesultanan di Nusantara yang tidak terlalu besar, akan semakin sulit mengungkapkan sejarah dan perkembangannya. Oleh sebab itu, studi tentang Kesultanan Islam di Jambi termasuk kajian yang agak terabaikan. Padahal, menurut Azyumardi Azra Jambi termasuk salah satu wilayah di kepulauan Nusantara yang paling awal disinggahi oleh

${ }^{1}$ Komaruddin Hidayat dan Ahmad Gaus AF, (ed). Menjadi Indonesia: 13 Abad Eksistensi Islam Di Bumi Nusantara.(Jakarta: Yayasan Festival Itiqlal dan Mizan, 2006), hal. 15

${ }^{2}$ Karel A. Steenbrink. Beberapa Aspek Tentang Islam Di Indonesia Abad Ke-19. (Jakarta: Bulan bintang, 1984), hal. 3 pedagang muslim dari Arab. ${ }^{3}$ Menurut Azyumardi Azra, pada awalnya pembentukan dan perkembangan suatu kesultanan adalah kelanjutan dari proses Islamisasi di Nusantara. ${ }^{4}$ Selain itu, konversi massal penduduk Nusantara ke dalam Islam beriringan dengan pertumbuhan masa perdagangan yang mengakibatkan terbentuknya kota-kota pelabuhan, kemudian berkembang menjadi entitas politik muslim. Salah satu tradisi politik Islam yang menonjol ialah penekanan pada hubungan antara Sultan dan ulama secara kokoh.

Sejarah kesultanan di Nusantara penuh dengan ketegangan dan konflik, hal ini menyebabkan mudahnya Imperialisme Barat menjajah Nusantara. Hal ini bukan karena kekuatan militernya yang sangat besar tetapi karena kelemahan internal kesultanan di Nusantara yang sering berperang, intrik, dan berusaha saling menguasai. Satu-persatu kesultanan di Nusantara dikuasai, dan Imperialisme Barat mengambil keuntungan besar melalui jalur perdagangan yang dikuasai oleh kerajaan. Kesultanan yang terlalu keras memberikan perlawanan diancam akan dihapuskan oleh Imperialisme Barat. $^{5}$ Di Pulau Sumatera, Provinsi Jambi merupakan bekas wilayah Kesultanan Melayu Islam Jambi (1460-1901 M). Pada masa kepemimpinan Orang Kayo Hitam (anak dari Datuk Paduko Berhalo dengan Putri Selaro Pinang Masak) pusat kerajaan Melayu

${ }^{3}$ Azyumardi Azra, Jaringan Ulama Timur Tengah dan Kepulauan NusantaraAbad XVII dan XVIII: Melacak Akar-akar Pembaharuan Pemikiran Islam Di Indonesia. (Bandung: Mizan, 1994), hal. 42

${ }^{4}$ Azyumardi Azra. Renaisans Islam Asia Tenggara: Sejarah, Wacana, dan Kekuasaan. (Bandung: Rosda Karya, 1999), hal. 89

${ }_{5}^{5}$ Bernard H. M Vlekke. Nusantara: Sejarah Indonesia. (Jakarta: KPG, Freedom Institute dan Balai Pustaka, 2008), hal. 183 
dipindahkan dari Muara Sabak (Muara Jambi) ke Kota Jambi. Penempatan Kota Jambi menjadi pusat kerajaan dikenal dengan sebutan Tanah Pilih. ${ }^{6}$ Pada tahun 1500 M, Orang Kayo Hitam mengumumkan bahwa Kerajaan Melayu Tanah Pilih Jambi adalah Kerajaan Islam, agama Islam adalah agama kerajaan dan agama penduduk Melayu Tanah Pilih adalah Islam, dan Tanah Pilih berserambi Aceh, Aceh berserambi Mekkah. $^{7}$

Pada masa kepemimpinan Sultan Abdul Kahar (1615-1643 M), Kesultanan Melayu Jambi didatangi oleh Kolonial Belanda dengan berlabuhnya 2 buah kapal dagang Belanda, mereka mendapat izin untuk mendirikan sebuah kantor Kompeni di Jambi untuk pembelian lada dan hasil hutan. Namun, loji dagang Belanda terpaksa ditutup atau dibubarkan karena tidak dapat berhubungan dengan rakyat Jambi. Tindakan bangsa Belanda yang datang ke Jambi untuk melaksanakan sistem monopoli perdagangan serta adanya usaha hendak menanamkan kekuasaan di daerah ini mendapat perlawanan rakyat Jambi. Di samping itu, pada saat kedatangan Belanda ke Jambi, rakyat Jambi penganut agama Islam yang taat. Perbedaan agama dengan bangsa Belanda yang ingin memerintah dan mengatur kehidupan mereka telah menimbulkan kebencian seluruh rakyat, karena hal ini bertentangan dengan prinsip agama Islam yang telah mereka anut selama ini. ${ }^{8}$ Tidak hanya perbedaan agama saja yang menyebabkan perlawanan terhadap Belanda, tetapi ada beberapa sebab lain seperti ikut campurnya Belanda di dalam pemerintahan, kesewenang-wenangan Belanda didalam perdagangan, dan lain sebagainya. Perlawanan rakyat Jambi ini digerakkan oleh SultanSultan serta pejuang-pejuang rakyat Jambi lainnya.

${ }^{6}$ Muchtar Agus Cholif. Timbul Tenggelam Persatuan Wilayah Luak XVI Tukap Khunut di Bumi Undang Tambang Teliti. (Jambi 1 Januari 2009) hal. 76

${ }^{7}$ Ibid., hal 107

${ }^{8}$ Masjkuri. Sultan Thaha Saifuddin.Jakarta: DEPDIKBUD Proyek Inventarisasi dan Dokumentasi Sejarah Nasional, 1985), hal. 21
Pada masa kepemimpinan Sultan Muhammad Fachruddin (1833-1844 M) yang merupakan pengganti Sultan-sultan Kesultanan Melayu Jambi sebelumnya, sering mendapat serangan dari Belanda sampai melakukan kesepakatan dengan Belanda secara terpaksa. Meskipun sultan atau pemimpin Kesultanan Melayu Jambi terus berganti namun Kolonial Belanda terus berkuasa dan terus menekankan rakyat meskipun selalu mendapat perlawanan dari rakyat. Dengan demikian, Belanda berhasil membuat perjanjian denga Sultan Muhammad Fachruddin. Sultan Muhammad Fachruddin wafat pada tahun 1841 M, kekusaan dilanjutkan oleh saudaranya Pangeran Ratu abdurrahman Nazaruddin. Namun perjanjian yang telah disepakati dengan sultan sebelumnya juga tidak berubah dan terus berlanjut sampai pada kekuasaan Sultan Thaha Saifuddin. Pada saat Sultan Thaha Saifuddin naik tahta, semua perjanjian yang disepkati oleh ayahnya (Sultan Muhammad Fachruddin) dibatalkan dengan spontan semua perjanjian dengan Belanda yang hanya menguntungkan pihak Belanda. ${ }^{9}$ Hal tersebut membuat pihak Belanda menyatakan perang dengan Sultan Thaha Saifuddin, pererangan yang tidak mengenal kata damai. Sikap Sultan Thaha Saifuddin yang non kooperatif terhadap Belanda, membuat Belanda melakukan permusuhan dengan Sultan.

Sultan Thaha Saifuddin tidak pernah dapat ditangkap oleh Belanda dan beliau gugur sebagai ksatria di tengah perperangan dengan Kolonial Belanda. Meskipun Sultan Thaha gugur, tetapi beliau gugur dalam berperang meawan Belanda. Sampai Sultan Thaha Saifuddin wafat, beliau tidak pernah melakukan perjanjian sedikitpun dengan pihak Belanda. Sultan Thaha Saifuddin meninggal

${ }^{9}$ Mirnawati. Kumpulan Pablawan Indonesia Terlengkap. (Jakarta: CIF, 2012), hal. 48 
di Muara Tebo pada tahun 1904 M. ${ }^{10}$ Dengan demikian, fokus pembahasan ini adalah Perlawanan Kesultanan Melayu Jambi Terhadap Kolonial Belanda: Kasus Sultan Muhammad Fachruddin (1833-1844 M) dan Sultan Thaha Saifuddin (1855$1904 \mathrm{M})$.

Artikel ini memfokuskan permasalahan tentang apa faktor penyebab terjadinya perlawanan Sultan Muhammad Fachruddin dan Sultan Thaha Saifuddin terhadap Kolonial Belanda, bagaimana strategi-strategi Sultan Muhammad Fachruddin dan Sultan Thaha Saifuddin dalam melawan Pemerintah Kolonial Belanda, dan bagaimana bentuk-bentuk perlawanan Sultan Muhammad Fachruddin dan Sultan Thaha Saifuddin terhadap Kolonial Belanda.

\section{METODE PENELITIAN}

Pada penelitian ini penulis menggunakan yang lazim dipergunakan dalam penelitian sejarah ${ }^{11}$ dan lebih menekankan pada aspek historis. Untuk mendapatkan fakta-fakta yang lebih akurat, maka penelitian ini menggunakan pendekatan kualitatif dengan metode historis. Pendekatan ini ditujukan untuk menjangkau sumber secara lebih luas dan kritis.

Adapun langkah-langkah yang digunakan ialah: Heuristik, mencari dan mengumpulkan sumber atau bahan sebanyak mungkin tanpa adanya batasan yang sesuai dengan topik pembahasan ini. Sumber-sumber tersebut diarahkan kepada arsiarsip pemerintah Kolonial Belanda dan Pemerintah daerah sebagai sumber primer. Arsip-arsip itu adalah; Politic Verslag, Staatsblad, naskah-naskah, dan arsip pemerintah daerah yang berhubungan dengan pembahasan ini. Kemudian langkah selanjutnya ialah verifikasi atau kritik sumber, digunakan untuk

${ }^{10}$ Eddy Soetrisno dan Elizabeth Tara, MD. 100 Pabla wan Nasional dan Sejarah Perjuangannya.(Jakarta:Ladang Pustak a \& Intimedia, 2001), hal. 12

${ }^{11}$ Irhash A Shamad. Ilmu Sejarah. (Jakarta: Hayfa Press, 2004), hal. 89 mengetahui orisinalitas atau keaslian sumber dan kredibilitas atau kesahihan sumber.

Selanjutnya dilakukan Interpretasi atau penafsiran sejarah seringkali disebut juga dengan analisis sejarah, merupakan kegiatan menguraikan, menafsirkan, dan menganalisa beberapa keterangan dari sumber-sumber data. Langkah yang terakhir ialah penulisan, Penulisan ini akan menggunakan bentuk penulisan sejarah yaitu sesuai dengan urutan waktu dan peristiwa yang terjadi secara sistematis.

Dalam mendeskripsikan peristiwa ini penulis menggunakan deskriptif analitis, dalam hal ini penulis akan menjawab pertanyaan apa dan bagaimana berdasarkan fakta-fakta yang ditemukan.

\section{SULTAN MUHAMMAD FACHRUDDIN (1833-1844 M)}

Mengenai kapan dan di mana Sultan Muhammad Fachruddin dilahirkan tidak diketahui sampai sekarang. Sejak kecil Muhammad Fachruddin sudah dilatih dan dididik dalam ilmu pemerintahan, agama, dan lain sebagainya. Hal ini terbukti ketika Sultan berada di bawah kekuasaan Belanda. Sultan tidak pernah berhenti berjuang untuk melawan Kolonial Belanda, meskipun ia mengetahui bahwa wilayah Kesultanan Melayu Jambi dikuasai oleh Belanda.

Di antara faktor penyulut perlawanan yang digalang oleh Sultan Muhammad Facruddin adalah faktor politik dan ekonomi.

Faktor politik dan pemerintahan. Pada tahun 1812 M Sultan Mas'ud Badaruddin (Sultan Ratu Ingologo) meninggal dunia, pemerintahan Kesultanan Jambi diteruskan oleh anaknya Raden Denting (Sultan Agung Sri Ingologo) yang disebut Sultan Muhammad Mahidin. Pada masa kepemimpinan Sultan Muhammad Mahidin, daerah Palembang mengalami situasi genting yaitu terjadinya perperangan dengan pihak penjajah seperti Inggris. Meskipun Inggris kalah dalam perperangan tersebut, tetapi Kolonial Belanda mulai masuk dan mempengaruhi politik dan 
ekonomi Palembang sehingga ketegangan terjadi antara Belanda dan Palembang.

Sehubungan dengan itu, Sultan Muhammad Mahidin memerintahkan putranya Pangeran Ratu Muhammad Fachruddin membawa pasukannya berangkat ke Palembang untuk membantu Sultan Mahmud Badaruddin dalam perang melawan Belanda. Dari sanalah mula terjadinya perlawanan Sultan Muhammad Fachruddin terhadap Belanda.

Faktor ekonomi. Pertengahan tahun 1833 M, seorang komisaris Jenderal Belanda bernama Van Den Bosch datang ke Sumatera dengan tujuan untuk menguasai pantai bagian barat dan bagian timur, terutama muara-muara sungai. Dengan menguasai muara-muara sungai ini Belanda berharap dapat memblokir perdagangan di daerah pedalaman Jambi. Di daerah perairan laut Jambi sering terjadi perampokan bajak laut, hal ini menimbulkan gangguan keamanan bagi pelayaran di laut. Dengan demikian Sultan Muhammad Fachruddin meminta bantuan kepada Van den Bosch untuk mengusir para perampok. Permintaan Sultan Muhammad Fachruddin diterima oleh Van Den Bosch, dan Belanda melakukan patroli laut untuk mengusir bajak laut dari perairan laut Jambi. Belanda berhasil melaksanakan tugas tersebut. ${ }^{12}$ Kesediaan Van Den Bosch memenuhi permintaan Sultan Jambi karena permintaan tersebut sejalan dengan kebijakan Van den Bosch di Sumatera, yang menghendaki perluasan pengaruh Belanda, ${ }^{13}$ yang selama ini terhalang oleh kekurangan informasi tentang wilayah Jambi.

Sesampainya Belanda di wilayah Kesultanan Melayu Jambi, Belanda langsung ikut campur dalam perekonomian dan perdagangan. Mereka memaksa rakyat Kesultanan untuk memberikan hasil dari pertanian mereka ke Belanda atau dengan kata lain

${ }^{12}$ Elsbeth Locher-Scholten. Kesultanan Sumatra dan Negara Kolonial, hubungan Jambi-Batavia (1830-1907) dan Bangkitnya Imperialisme Belanda. Terjemahan; Noor Cholis. (Jakarta: Banana, KITLV, 2008), hal. 76

${ }^{13}$ Ibid., hal. 70
Belanda membeli hasil panen rakyat dengan harga rendah. Sedangkan didalam perdagangan, Belanda melarang rakyat Kesultanan Melayu Jambi melakukan hubungan dagang dengan daerah lain, kecuali dengan pihak Belanda.

\section{Bentuk Konkrit Perlawanan}

Mengadakan pertemuan dengan Sultan Mahmud Badaruddin (Palembang). Pertemuan tersebut bermaksud melakukan pembangunan benteng-benteng pertahanan di tengah Sungai Musi. Beberapa kali Belanda melakukan penyerangan terhadap benteng tersebut tetapi tidak berhasil. Dengan demikian, wilayah Kesultanan Melayu Jambi untuk sementara bisa tenang tanpa ada keributan dan peperangan yang disebabkan oleh Belanda.

Pasukan Jambi membuat benteng pertahanan di tengah sungai Musi berupa pulau buatan. Kapal-kapal dan perahu-perahu sukarelawan dari Bugis, Lingga, Sambas dan Riau juga dipersiapkan untuk memudahkan transportasi dalam menghambat gerak maju pasukan Belanda.

Mengutus anaknya Raden Thaha yang masih berusia 21 tahun mengunjungi Malaya (sekarang Malaysia), Singapura dan Patani guna memperkuat hubungan dagang. ${ }^{14}$ Jika hubungan dagang Jambi sudah kuat dengan negara-negara tetangga, otomatis juga akan berpengaruh kepada kekuatan politik Jambi.

Pada April 1833 M, Sultan Muhammad Fachruddin telah beberapa kali meminta pertemuan dengan otoritas Belanda di Palembang, tetapi tidak mendapat tanggapan, bahkan tidak diperdulikan dan tidak dianggap penting. ${ }^{15}$ Atas inisiatif sendiri, Sultan bersama pasukannya langsung menuju

${ }^{14}$ Kunjungan tersebut juga diadakan untuk meninjau perkembangan pendidikan dan perkembangan lainnya. Untuk menambah semangat memperbaiki dan meningkatkan segisegi kehidupan rakyat Jambi.

15ANRI, algemeene Secretarie, Beschrijving 11 September 1834, No. 4 
Rawas. Akan tetapi kedatangan Sultan Muhammad Fachruddin beserta pasukannya justru menimbulkan ketegangan di Kesultanan palembang dan otoritas Belanda di Palembang, sehingga di utuslah seseorang untuk memastikan tujuan Sultan Muhammad Fachruddin. ${ }^{16}$ Kedatangan Sultan Muhammad Fachruddin beserta pasukannya di wilayah kekuasaan kolonial di Palembang tidak diterima, sehingga konflik bersenjata tidak terhindarkan lagi.

Pada pertengahan Juli 1833 M, terjadi pertempuran antara Sultan Muhammad Fachruddin dengan Kolonial Belanda yang berlangsung hampir satu bulan. Karena kalah dalam teknologi persenjataan, pasukan Jambi pergi dari Palembang. Pada awal Agustus 1833 M, Sultan Muhammad Fachruddin melakukan penyerangan ke wilayahwilayah yang dikuasai Belanda, ${ }^{17}$ khususnya di Ulu Rawas. Berkaitan dengan sikap Sultan Muhammad Fachruddin yang melakukan penyerangan terhadap tempat-tempat yang dikuasai Belanda, maka pihak Belanda mengambil tindakan keras dengan memperketat pengawasannya di Muara Sungai Batanghari sampai ke Jambi Ulu.

Belanda memberangkatkan pasukannya besar-besaran menuju Rawas di bawah Komando Koff dan angkatan darat dibawah Kolonel A. V. Michiels untuk menggempur pasukan Sultan Muhammad Fachruddin. Perintah untuk Michiels adalah untuk menguasai Jambi termasuk Indargiri di bagian Utara jika ada tanda-tanda persekongkolan beserta sungai-sungai besar di Jambi dan Indragiri, selain itu juga membangun benteng permanen untuk pengontrolan. Sedangkan Koff berhasil memperkuat benteng VOC di Muara 1832, No. 4

${ }^{16}$ ANRI, algemeene Secretarie, Beschrijving 12 Juli

${ }^{17}$ Tim Penyusun. Republik Indonesia Propinsi Jambi. (Jambi: Pemerintah Provinsi Jambi, 2006) hal. 64
Kumpeh dan memblokade Sungai Batanghari. ${ }^{18} \mathrm{Hal}$ ini membuat perekonomian Kesultanan Melayu Jambi menyusut drastis. Kekuasaan Sultan Fachruddin akhirnya berhasil ditundukkan. Melihat keadaan yang menguntungkan itu maka Belanda memaksa Sultan Muhammad Fachruddin menandatangani surat perjanjian tanggal 14 November 1833 M di Sungai Baung. Perjanjian tersebut sangat terkenal dengan nama Piagam Sungai Baung. Adapaun isi Piagam Sungai Baung adalah sebagai berikut:

1. Negeri Jambi dikuasai dan dilindungi oleh Belanda

2. Pemerintah Belanda mempunyai hak untuk menempatkan kekuatan dalam daerah Jambi di mana perlu. ${ }^{19}$

Isi perjanjian Piagam Sungai Baung dirasakan sangat merugikan Kesultanan Melayu Jambi. Menjelang akhir tahun 1833 M, Belanda berhasil menguasai loji dagang di Muara Kumpeh dan Muara Sabak serta mendirikan pos penjagaan. Pada tanggal 15 Desember 1834 M Belanda mengusulkan kembali satu perjanjian yang dianggap lebih sempurna. Perjanjian yang disempurnakan itu ditandatangani Sultan Muhammad Fachruddin dan Pangeran Ratu Abdurrahman Marta Ningrat yang disaksikan oleh beberapa bangsawan Jambi dalam keadaan terpaksa. ${ }^{20}$ Dengan demikian Sultan Muhammad Fachruddin mengakui kedaulatan Kolonial Belanda di Jambi. ${ }^{21}$ Perjanjian yang disempurnakan ini ditandatangani pada tanggal 21 April 1835 M. Adapaun isi perjanjian yang telah disempurnakan tersebut antara lain sebagai berikut:

1. Pemerintah Belanda memungut cukai dari segala pemasukan dan pengeluaran barang

${ }^{18}$ Surat Perintah Kepada Michiels, 29 Juli 1833, no. 133. ANRI, Algemeene Secretarie, Gouvernementsbesluit, 20 September 1834, no. 4

${ }^{19}$ Tim Penyusun. Loc.Cit., hal. 64

${ }^{20}$ ANRI. Politic Verslag. Kontrakt Sulthan En Pangeran Ratu Van Djambi van 2 November 1858

${ }^{21}$ Robert Cribb and Audrey Kahin. Kamus Sejarah Indonesia. (Jakarta Komunitas Bambu, 2012), hal. 203 
2. Pemerintah Belanda berhak monopoli dalam hal penjualan garam

3. Pemerintah Belanda tidak memungut cukai lain

4. Pemerintah Belanda tidak akan ikut campur tangan dalam urusan tata negara dalam negeri Kesultanan Melayu Jambi, dan tidak akan mengganggu adat istiadat dalam negeri, kecuali dalam hal pengelolaan cukai yang akan dipungut oleh pemerintah Belanda

5. Kepada Sultan dan Pangeran Ratu diberikan uang $f .8000$ setahun sebagai ganti rugi. ${ }^{22}$

Walaupun Sultan Muhammad Fachruddin telah menandatangani Piagam Sungai Baung tersebut, Sultan tetap berupaya dengan gigih berjuang untuk mengusir Belanda dari Negeri Jambi. Namun upaya untuk berlaku keras melawan Belanda tersebut menghadapi kendala karena terikat oleh perjanjian yang telah ditandatangani. Pada tahun 1844 M, Sultan Muhammad Fachruddin wafat. Ia digantikan oleh saudaranya Pangeran Ratu Abdurrahman Nazaruddin. Selama Abdurrahman Nazaruddin memerintah, ia patuh kepada pemerintahan Kolonial Belanda. Ia tidak pernah mencoba melakukan perlawanan terhadap Kolonial Belanda sampai pada masa akhir pemerintahannya yaitu tahun $1855 \mathrm{M}$.

\section{SULTAN THAHA SAIFUDDIN (1855-1904 M)}

Sultan Thaha Saifuddin adalah anak dari Sultan Muhammad Fachruddin, beliau dilahirkan di Keraton Tanah Pilih Kampung Gedang, Kerajaan Jambi pada tahun 1816 M. Pada waktu kecil Sultan Thaha Saifuddin diberi nama Raden Thaha Adiningrat. Setelah selesai menuntut pengetahuan di Aceh, Sultan Aceh menganugerahi beliau gelar "Saifuddin" berasal dari bahasa arab yang berarti "pedang agama". 23 Sejak kecil Sultan Thaha sudah

${ }^{22}$ Elsbeth Locher-Scholten. Op.cit., hal. 89

${ }^{23}$ Zuraima Bustaman, M. Yusuf, dkk. Biografi Pablawan Nasional Sultan Thaha Saifuddin. (Jambi: CV. Lazuardi Indah Jambi, 1996), hal. 8 memperlihatkan tanda-tanda kecerdasannya, suka bergaul dengan rakyat biasa, tangkas, rendah hati berani serta gesit. Sultan Thaha sudah mendapat pendidikan ilmu tauhid dari ayahnya. Oleh karena itu sejak kecil, Sultan Thaha taat menjalankan ajaran agama Islam dan kepercayaan yang penuh kepada keEsa-an Tuhan. Beliau memiliki sifat-sifat yang luar biasa. Beliau seorang yang pemberani dan ulet dalam menghadapi segala macam pekerjaan. ${ }^{24}$

Di antara faktor pemicu perlawanan Sultan Thaha Saifuddin adalah adanya tekanan penguasaan Belanda melalui perjanjian Sungai Baung (Rawas) tanggal 14 November 1833 M dengan Letkol Michiels yang ditandantangani oleh Sultan Muhammad Fachruddin begitu menyakitkan hati Sultan Thaha. ${ }^{25}$ Dampak dari perjanjian tersebut, berdirilah markas patroli Belanda di Muara Kumpeh yang sejak semula dipandang strategis sebagai pintu keluar masuknya pelayaran Dataran Aliran Sungai (DAS) Batanghari. Tempat yang sangat bagus untuk pengawasan pusat Pemerintahan Kesultanan Jambi baik pertahanan maupun ekonomi melalui perdagangan hasil bumi, hasil perkebunan dan hasil hutan Jambi.

Selain itu, karena berdirinya markas Belanda di Muara Kumpeh, kemudian Belanda menambah pasukannya dari Batavia ke Muara Kumpeh di bawah pimpinan Mayor Van Langen dengan 30 buah kapal perang dan 800 personil serdadu Belanda pada tanggal 25 September $1858 \mathrm{M}$.

Pada masa Sultan Thaha Saifuddin menjabat sebagai Perdana Menteri tahun 1841 M, agama Islam sudah meluas. Akan tetapi, rakyat Jambi masih banyak yang belum tahu tentang tulisan dan bacaan huruf Arab. Oleh karena itu, terlebih dahulu sultan mempersatukan seluruh rakyat Jambi dengan semangat keislaman guna

\footnotetext{
${ }^{24}$ Tamar Djaja, Riwayat Hidup Orang-orang Besar Tanah Air. (Jakarta: Bulan B intang, 1966), hal. 479

${ }^{25}$ Usman Meng. Napak Tilas Liku-liku Provinsi Jambi (Kerajaan Melayu Kuno sampai dengan Terbentuknya Provinsi Jambi). (Jambi: Pemerintah Provinsi Jambi, 2006), hal. 11
} 
mengusir Kolonial Belanda yang dikatakannya sebagai orang kafir dari seluruh wilayah Jambi. Sultan Thaha dalam memberikan dakwah kepada rakyat sering mengutip ayat-ayat Al-Qur'an ${ }^{26}$. Di antaranya surat An-nisa' ayat 144:

"Wabai orang-orang yang beriman! Janganlah kamu menjadikan orang-orang kafir sebagai pemimpin selain dari orang-orang mukmin. Apakah kamu ingin memberi alasan yang jelas bagi Allah (untuk menghukummu)?,27

dan Surat Al-Maidah ayat 51:

"Wabai orang-orang yang beriman! Janganlah kamu menjadikan orang Yabudi dan Nasrani sebagai teman setia(mu); mereka satu sama lain saling melindungi. Barangsiapa di antara kamu yang menjadikan mereka teman setia, maka sesunggubnya dia termasuk golongan mereka. Sungguh, Allah tidak memberi petunjuk kepada orang-orang yang zalim.”

Sultan Thaha berkali-kali menyampaikan ayat-ayat tersebut, dalam dakwahnya dengan maksud menanamkan perasaan keagamaan dan kebangsaan kepada rakyatnya. Sehingga rakyat rela mati demi mempertahankan agama dan tanah airnya, serta berani menentang dan mengusir penjajah Belanda. Di samping itu, selain untuk memperkuat rasa keimanan rakyat terhadap Allah SWT. Sultan Thaha juga berusaha untuk mencerdaskan rakyatnya. Untuk itu Sultan Thaha mendatangkan tenaga ulama dari luar negeri, seperti dari Mesir dan Patani, bahkan juga didatangkan ulama dari Minangkabau.

Sehubungan dengan itu, kondisi agama pada masa pemerintahan Sultan Thaha Saifuddin semakin membaik dari sebelumnya. Karena pada masa Sultan sebelumnya rakyat Jambi belum begitu mengenal dengan tulisan, bacaan huruf arab dan pendidikan tentang keagamaan, akan tetapi pada masa Sultan Thaha Saifuddin rakyat Jambi sudah mulai mengenal tentang akan ilmu pengetahuan

\footnotetext{
${ }^{26}$ Elsbeth Locher-Scholten. Op.cit., hal. 34

${ }^{27}$ Dalam bahasa arab, kata $W$ ali yang jamaknya "Awliya" berarti "teman yang akrab" juga berarti "pelindung atau penolong".
} itu, kelompok ulama mendapat peranan penting dalam pemerintahan, bahkan agama dijadikan dasar utama dalam pemerintahan. Pada masa pemerintahan Sultan Thaha inilah mula pertama diadakannya jabatan hakim agama atau "qadhi" di daerah Jambi.

Strategi di atas, disamping mempertebal keimanan rakyat dengan menumbuhkan semangat patriotik untuk melawan penjajah Belanda. Sultan Thaha juga telah mampu menunjukkan jiwa kepemimpinanya kepada rakyat dengan menggunakan strategi tersebut. Selain itu, sebagai seorang pemimpin perang gerilya Sultan Thaha juga menggunakan strategi sebagai berikut:

1. Pantang bertemu langsung dengan (utusan) Belanda dalam setiap perundingan yang digagas Belanda yang sebenarnya merupakan wahana lobi untuk menekan Sultan agar takluk dan terikat oleh perjanjian tersebut. Pantangan ini sangat mendukung strategi Sultan Thaha dalam perjuangannya.

2. Perjuangan yang dilakukan dipatri oleh sumpah setia untuk memegang teguh bahwa "Sultan tidak mati”, dengan maksud agar semangat para rakyat tidak pernah pudar dan takut dalam melawan penjajah Belanda. ${ }^{28}$

3. Pemindahan markas dan persebaran front perlawanan dilakukan dengan cepat. Hal ini menunjukkan bahwa perlawanan yang dilakukan teratur dan sesuai dengan perintah Sultan Thaha Saifuddin.

4. Mengadakan hubungan "perdagangan" dengan pihak-pihak luar seperti Turki, Inggris atau Amerika yang ada di Semenanjung Malaka, melalui sistem barter hasil hutan dan perkebunan ditukar dengan peralatan senjata maupun suplai kebutuhan hidup Sultan dan pasukannya di daerah huluan dasar aliran sungai

${ }^{28}$ Usman Meng. Op.cit., hal. 22 
Batanghari. ${ }^{29}$ Selain itu juga tanpa sepengetahuan para pejabat Kolonial Belanda, Sultan Thaha Saifuddin mengirimkan Pangeran Ratu ke Singapura pada Oktober 1857 M tidak untuk membicarakan perdagangan melainkan melakukan sebuah misi diplomatik. ${ }^{30}$ Sultan Thaha Saifuddin ingin mengirimkan permintaan tertulis kepada Sultan Turki lewat Singapura, untuk memperoleh cap yang menyatakan bahwa kerajaan Islam Jambi di bawah pimpinan Sultan Thaha Saifuddin dan di mana pihak luar tidak punya hak.

Sultan Thaha Saifuddin menggunakan benteng, kampung, dan rumah-rumah yang diperkuat, yang hanya bisa direbut dengan pertarungan duel dengan bayonet. Kemudian, Keraton juga dilindungi oleh rawa-rawa sehingga maneuver memutar pasukan Belanda tidak bisa masuk. Sehubungan dengan itu, persiapan yang dilakukan sejak bulan Agustus 1858 M dan ekspedisi militer tanggal 6 September $1858 \mathrm{M}$ di pimpin oleh Mayor Van Langen dari Muara Kumpeh untuk meneyrang Keraton Jambi dari segala penjuru secara diam-diam, ${ }^{31}$ mendapat perlawanan yang sengit dari Sultan Thaha jauh lebih sengit ketimbang apa yang diperkirakan oleh Belanda.

\section{Bentuk-bentuk Perlawanan Sulthan Thaha}

Sulthan Thaha memberikan perlawanan dengan cara non fisik dan fisik. Bentuk non-fisik salah satunya dengan cara Menanamkan rasa kebencian terhadap Belanda. Sultan Thaha Saifuddin bercita-cita untuk menyebar agama Islam,

${ }^{29}$ Junaidi T. Noor. Mencari Jejak Sangkala. Jambi: Pusat Kajian Pengembangan Sejarah dan Budaya Jambi, 2007), hal. 142-143

${ }^{30}$ Mardanas Sofwan. Riwayat Hidup dan Perjuangan Sultan Thaha. (Jakarta: Proyek Biografi Pahlawan Nasional Departemen Pendidikan dan Kebudayaan, 1976), hal. 14

${ }^{31}$ ANRI, Politic Verslag. Djambangan. Een der toppen van het nog overgebleven gedeelte van den ringwal van den ouden Ajegvukkaan (zie aldaar). No. 611, tanpa tahun. mencerdaskan rakyatnya dan memberi ketenangan dan kedamaian kepada seluruh rakyatnya. Akan tetapi, Sultan menyadari rencananya itu tidak akan berhasil apabila Kolonial Belanda masih berada di Jambi mencampuri segala urusan pemerintahan Kesultanan. Oleh sebab itu, Sultan Thaha Saifuddin mendatangkan ulama dari luar negeri untuk mengajarkan rakyatnya. Selain itu juga Sultan Thaha Saifuddin menanamkan jiwa patriot kepada seluruh rakyatnya agar suatu waktu jika ada Belanda menyerang, rakyat tidak pernah takut dan gentar untuk melawan Belanda. Selain itu dengna cara membatalkan Perjanjian. Sultan membatalkan piagam Sungai Baung yang ditandatangani oleh ayahnya tanggal 14 September $1833 \mathrm{M}, 32$ perjanjian tambahan tanggal 15 Desember $1834 \mathrm{M}^{33}$ dan perjanjian tanggal 21 April $1835 \mathrm{M}^{34}$

Selain non-fisik, bentuk perlawanan fisik yang dilancarkan Sulthan Thaha adalah dengan mengerahkan kekuatan militer. Pada 2 September 1858 M datang utusan Belanda bermaksud bertemu Sultan Thaha Saifuddin untuk menyampaikan isi perjanjian dan sekaligus menyampaikan ultimatum Gubernur Jenderal Nederlandsch Indie di Batavia. Ekspedisi militer ini dilarang masuk keraton dan tidak diperkenankan bertemu Sultan. Target atau tujuan Kolonial Belanda adalah menangkap hidup

${ }^{32}$ Junaidi T. Noor. Op.cit., hal, 66

${ }^{33}$ Perjanjian tambahan tanggal 15 Desember $1834 \mathrm{M}$ berisi: 1), Pemerintah Hindia Belanda berhak memungut cukai atas barang-barang impor dan expor. 2), Pemerintah Hindia Belanda berhak memonopoli penjualan garam. Dan 3), Pemerintah Hindia Belanda tidak akan mengurus cukai yang lain. Zuraima Bustaman, M. Yusuf, dkk. Op.cit.,hal. 53

34 Perjanjian tanggal 21 April $1835 \mathrm{M}$ merupakan tambahan dari perjanjian sebelumnya yang berisi: 1), Pemerintah Hindia Belanda berhak memungut cukai atas barang-barang impor dan expor. 2), Pemerintah Hindia Belanda berhak memonopoli penjualan garam. Dan 3), Pemerintah Hindia Belanda tidak akan mengurus cukai yang lain. 4). Pemerintah Hindia Belanda tidak akan mencampuri urusan Pemerintah dalam negeri dan tidak akan mengganggu adat istiadat dalam negeri, kecuali dalam hal penggelapan cukai yang telah menajdi hak Pemerintah Hindia Belanda untuk memungutnya. Dan 5). Kepada Sultan dan Pangeran Ratu diberikan uang sebesar $f 8.600$ setiap tahun. Ibid., 
atau mati Sultan Thaha Saifuddin dan Pangeran Dipo serta pengikutnya. dengan demikian, Belanda terus menyerang dan mengepung wilayah Kesultanan Melayu Jambi agar bisa menangkap Sultan Thaha Saifuddin. Akan tetapi, Sultan Thaha Saifuddin kalah dalam persenjataan dengan demikian Kesultanan Melayu Jambi dapat dikuasai oleh Belanda.

Setelah keraton dikuasai oleh Belanda, Sultan Thaha Saifuddin pindah ke wilayah Muara Tembesi. Sultan Thaha berhasil menyusun pemerintahan baru yang berpusat di Muara Tembesi, mulailah ia menanamkan semangat juang secara lebih intensif kepada rakyat. Oleh karena itu, Sultan Thaha Saifuddin memberikan penerangan kepada rakyat tentang tujuan perjuanganya, maka beliau dengan jelas menyampaikan "Setih Setio" yang di ikuti oleh rakyat dengan penuh semangat untuk segera melaksanakannya.

Kolonial Belanda yang mengakui posisi Sultan Thaha Saifuddin yang kuat itu mulai menjalankan politik adu domba sesama rakyat Jambi. Mereka mencari keluarga Sultan Thaha Saifuddin yang bersedia diangkat menjadi sultan Jambi dengan syarat bersedia untuk tunduk dan mentaati perjanjian yang dibuat dengan Belanda. Ada 3 orang Sultan Bayang yang di angkat oleh Kolonial Belanda masing-masing adalah sebagai berikut: ${ }^{35}$

Pada tanggal 2 Nopember 1858 M Kolonia Belanda mengangkat Abdurrahman Nazaruddin dengan gelar Sultan Ratu Ahmad Nazaruddin dan Pangeran Martadiningrat sebagai Pangeran Ratunya (1858-1881 M)

Pada bulan Juli 1881 M Kolonial Belanda mengangkat Pangeran Ratu Martadiningrat dengan gelar Sultan Ratu Muhammad Mahiluddin

${ }^{35}$ Departemen Pendidikan dan Kebudayaan Direktorat Jenderal Kebudayaan Direktorat Sejarah dan Nilai Tradisional Proyek Penelitian dan Pengkajian Kebudayaan Nusantara. Penelitian dan Pengkajian Naskah Kuno Daerah Jambi II. 1989, hal. 86
(Muhyidin) (1881-1885 M) dan sebagai Pangeran Ratunya ialah Pangeran Surio dengan gelar Pangeran Ratu Cakra Negara.

Pada bulan Juli 1886 M Kolonial Belanda mengangkat Pangeran Ratu Cakra Negara menjadi Sultan dengan gelar Sultan Ahmad Zainuddin (1886-1899 M) dan Pangeran Ratunya ialah putra ke 3 Sultan Thaha Saifuddin yang belum cukup umur (berusia 4 tahun) bernama Pangeran Anom Kesumoyudo. Karena belum cukup umur maka Kolonial Belanda mengangkat Pangeran Marta Jayakesuma sebagai Pangeran Ratu. ${ }^{36}$

Sesuai dengan apa yang diinginkan oleh Kolonial Belanda, maka setelah Sultan Bayang dinobatkan menjadi Sultan Jambi oleh Belanda timbul perpecahan di kalangan keluarga Kesultanan dan rakyat Jambi. Tetapi sebagian besar rakyat Jambi hanya mengakui Sultan Thaha Saifuddin sebagai Sultan Jambi yang sah. Hal ini disebabkan Sultan Thaha Saifuddin yang memegang tandatanda kebesaran dan alat-alat upacara kesultanan antara lain "Keris Siginjai" yang merupakan lambang kesultanan. Setelah Kolonial Belanda mengetahui kemampuan Sultan Thaha Saifuddin, pada tahun 1882 M Belanda menawarkan konsep perjanjian baru kepada Sultan yang isinya sebagai berikut: "Jika Sultan Thaha Saifuddin bersedia menyerahkan diri kepada pemerintah Belanda dan mau mengakui Sultan Muhammad Mahiluddin yang diangkat Belanda serta perjanjian baru yang di tandatanganinya," maka:

1. Sultan Thaha Saifuddin berhak menerima uang tahunan dari pemerintah Belanda.

2. Sultan Thaha Saifuddin akan diangkat sebagai pembesar negeri.

3. Sultan Thaha Saifuddin akan diberi pengganti kerugian sebesar $f$. 500 ,- sebulan. ${ }^{37}$

\footnotetext{
${ }^{36}$ ANRI, Politic Verslag. Djambangan. Een der toppen van het nog overgebleven gedeelte van den ringwal van den ouden Ajegvukkaan (zie aldaar). No. 611, tanpa tahun.

${ }^{37}$ Departemen Pendidikan dan Kebudayaan Provinsi Jambi. Monografi Daerah Jambi, tahun 1975, hal. 44
} 
Permulaan dari perlawanan rakyat Jambi terhadap Belanda belum berupa perlawanan bersenjata, tetapi merupakan pemboikotan penjualan hasil bumi. Sikap tidak senang rakyat Jambi terbukti dengan ditutupnya kantor dagang kompeni Belanda di Muara Kumpeh. Pada tanggal 25 September $1858 \mathrm{M}$ terjadi pertempuran antara pasukan Belanda dengan pasukan Sultan Thaha Saifuddin di Muara Kumpeh. Dalam perperangan ini, pasukan Sultan Thaha Saifuddin berhasil menenggelamkan kapal perang mmilik Belanda, sedangkan dari pihak Sultan Thaha gugur tiga orang panglima yang selalu mendampinginya dan pimpinan perang diserahkan kepada Raden Mat Tahir.

Di Muara Tembesi, Sultan Thaha Saifuddin menata ulang sistem pemerintahan, militer, taktik/strategi dan pembagian wilayah. Sejak Maret sampai Mei 1885 M hampir setiap hari di kota Jambi mendapat serangan dari pasukan Raden Anom dan Raden Kusin. Antara Jambi dan Kolonial Belanda saling serang-menyerang untuk memperebutkan lokasi benteng Belanda yang dijaga sangat ketat. Di samping itu, terjadi lagi pembunuhan terhadap dua orang Kolonial Belanda di balai pertemuan Jambi yang dilakukan oleh Raden Anom. Dalam peristiwa ini anak buah Raden Anom berhasil melarikan beberapa senjata Kolonial Belanda. Pada tahun yang sama Raden Anom beserta prajuritnya mengadakan serangan mendadak terhadap benteng Kolonial Belanda di Jambi yang menimbulkan banyak korban di pihak Belanda.

Masih dalam keadaan tegang pada tanggal 27 Agustus 1885 M kota Jambi diserang lagi. Namun serangan ini gagal dan pelaku penyerangan juga dipimpin oleh Raden Anom dan Raden Kusin. Pada tahun yang sama kapal perang Belanda dengan No.12 yakni kapal Houtman sedang diperairan menuju Jambi diserang dan dirampok segala isinya, lalu ditenggelamkan. Pada bulan April 1890 M kedudukan Belanda di Sorolangun Rawas diserang pula oleh Haji Kademang Rantau Panjang yang dibantu oleh beberapa Hulubalangnya antara lain: Depati Setyaraja Lubuk Gaung, Depati Setiyo, Depati Tabir Bangko, Nalo dan Depati Setya Nyata Talang Renah. Kemudian ketika Kolonial Belanda memusatkan perhatiannya ke Rawas, Sultan Thaha Saifuddin membentuk pasukan kuat yang dipimpin oleh Pangeran Haji Umar, Pangeran Dipo, Raden Pamuk, Raden Mat Tahir dan Raden Puang.

Sultan Thaha juga memerintahkan agar tiaptiap rumah memiliki sebuah selaras bedil dan tiap keluarga menyimpan padinya di hutan. Setelah segala ikhtiar dijalankan Sultan Thaha Saifuddin menganjurkan kepada seluruh rakyat untuk memperkuat kubu pertahanannya masing-masing dan meningkatkan sabotase. Apabila ada kesempatan yang baik, tanpa menunggu komando rakyat diperintahkan langsung saja bergerak. Anjuran dan perintah Sultan Thaha Saifuddin mendapat sambutan yang sangat baik dari rakyat.

Pada bulan Juni 1901 M, terjadi insiden di Muara Tembesi antara pihak belanda dan para pejuang Jambi dimulai dari adanya perjalanan pasukan Belanda melayari Sungai Tembesi. Perjalanan Belanda mencapai Dusun Pengidaran dan disini mereka mendapatkan jalan dblokir oleh penduduk. Kapal Belanda mencoba menembusnya, akan tetapi sesampai di Ladang Panjang mereka mendapatkan penduduk bersenjata senapan, parang, dan tombak berdiri di sepanjang tepian sungai. ${ }^{38}$

Dalam rangka penaklukan Jambi maka Kolonial Belanda memandang perlu menggempur Muara Tembesi sampai dikuasai. Untuk menguasai Muara Tembesi maka Belanda mengerahkan pasukan infanteri, artileri, zeni, kesehatan, angkutan dan kapal perang. Sedangkan persenjataan pasukan Sultan Thaha Saifuddin dilengkapi dengan senjata

${ }^{38}$ Lindayanti, dkk. Jambi dalam Sejarah 1500-1942. (Jambi: Pusat Kajian Pengembangan Sejarah dan Budaya Jambi, 2013), hal. 190 
bedil dan senjata lainnya. Namun, akhirnya Muara Tembesi tidak dapat bertahan lama dan pada tahun 1901 M Muara Tembesi jatuh ke tangan Kolonial Belanda. Setelah Muara Tembesi jatuh ketangan Kolonial Belanda maka Sultan Thaha Saifuddin dan pasukannya dipusatkan dan bertahan di sekitar sungai Tabir yakni di dusun Pematang, Tanah Garo.

Suasana yang di anggap tenang oleh Kolonial Belanda setelah menguasai Muara Tembesi, ternyata terganggu oleh penyerangan kedudukan kontroler di Sarolangun tanggal $30 \mathrm{Mei}$ 1901 M dan pada tanggal 6 Juni 1901 M beberapa pos di tepi sungai Batanghari juga diserang oleh para pengikut Sultan Thaha Saifuddin. Pasukan Belanda di seberang Muaro Tembesi berhasil dilenyapkan oleh Pasukan Sultan pada tanggal 11 Juli 1901 M dan tanggal 27 Juli 1901 M pasukan patroli Belanda ditembaki dengan gencar oleh pasukan Sultan. Pada tanggal 13 Juli 1901 M passukan Belanda yang sedang berpatroli di Singkut ditembaki sehingga satu orang juru tembak Belanda mati dan dua orang lainnya menderita luka. Serangan-serangan di Singkut tersebut mendorong Belanda menambah kekuatan pasukan Ambon dari batalyon gernizun Magelang. Perlawanan semakin seru walaupun akhirnya pasukan Sultan meninggalkan Singkut dan tidak seorangpun yang menyerah. Benteng-benteng perlawanan; Tanjung Limbur, Limbur, Merangin, Pelayangan, Sekancing, Limbur Tembesi, Datuk Nan Tigo, Kuto Rayo, Sungai Manau, Sungai Alai dan Muaro Siau secara berturut-turut berhasil diduduki pasukan Belanda. Namun demikian Sultan Thaha dan pasukannya masih tetap melakukan serangan-serangan secara bergerilya.

Pada tahun 1902 M, terjadi perlawanan rakyat di Tembesi Hilir di bawah komando Raden Mat Tahir dan Raden Seman. Perjuangan Raden Mat Tahir dalam melawan Belanda terus berlangsung meski secara berangsur makin lemah. Bersama dengan Pasirah Tahir dan Raden Su'ud,
Raden Mat Tahir mencoba menggalang kekuatan masyarakat dengan mengatasnamakan perintah dari Sultan. Pada pertengahan tahun 1903 M, Raden Mat Tahir bergerak ke Ulu Jangga dan dilanjutkan ke Ulu Batanghari. Sejak pertengahan tahun 1903 $M$ perlawanan rakyat Jambi berubah dari perlawanan lokal menjadi perlawanan seluruh rakyat Jambi. Perubahan ini disebabkan oleh peran dari Raden Mat Tahir yang bergerak tidak sebatas Air Hitam tetapi dia mengorganisir masyarakat di antara Ulu tembesi dan Ulu Batanghari.

Meskipun terjadi perperangan dimanadimana Kolonial Belanda tidak pernah menyerah untuk mencari keberadaan Sultan Thaha Saifuddin. Semua pasukan yang dikirim oleh Kolonial Belanda tersebut serentak menuju ke wilayah Betung Bedarah dimana tempat Sultan Thaha Saifuddin berada. Pada tanggal 25 April 1904 M, para pasukan diberangkatkan dan bertugas untuk melakukan penghadangan dan penyerbuan. Akan tetapi, pasukan Belanda tidak berhasil menemukan markas Sultan Thaha Saifuddin dan keesokan harinya tanggal 26 April mereka berhasil menemukan jejak yang diduga dapat menghantarkan ke markas Sultan Thaha.

Sultan Thaha membuktikan tekad perjuangannyan sampai ke titik darah penghabisan ke bumi persada ibu Pertiwi, seiring dengan munculnya matahari di ufuk Timur tanggal 27 April 1904 M Sultan Thaha Saifuddin gugur dalam kancah desingan peluru Kolonial Belanda dengan pedang masih tergenggam di tangan. ${ }^{39}$ Sebagai seorang panglima Sultan Thaha Saifudddin memegang prinsip sampai akhir hayatnya tidak pernah mau berunding dengan pihak Kolonial Belanda. Sultan Thaha Saifuddin cukup menyadari bahwa perundingan dengan pihak Kolonial Belanda pada intinya adalah pengekangan dan intervensi terhadap kedaulatan kesultanan Jambi.

${ }^{39}$ Junaidi T Noor. Op,cit., hal. 156 


\section{KESIMPULAN}

Demikian deskripsi perjuangan dari dua tokoh pahlawan di Nusantara dalam mempertahankan tanah air dari segala bentuk serangan penjajah. Khususnya untuk daerah Jambi. Sulthan Muhammad Facruddin dengan semangat juang dan Sulthan Thaha Saifuddin dengan kecerdasan dan kecerdikanya.

Meskipun keduanya belum mapu mengusir penjajah secara menyeluruh, setidaknya nilai-nilai perjuangan keduanya dapat menjadi contoh untuk dipanuti dan ditiru hingga zaman milenilal sekarang ini khusunya untuk awak Melayu Jambi dan sekitarnya.

\section{DAFTAR KEPUSTAKAAN}

ANRI, algemeene Secretarie, Beschrijving 11 September 1834, No. 4

ANRI, algemeene Secretarie, Beschrijving 12 Juli 1832, No. 4

ANRI, Politic Verslag. Djambangan. Een der toppen van het nog overgebleven gedeelte van den ringwal van den ouden Ajeg-vukkaan (zie aldaar). No. 611, tanpa tahun

ANRI. Politic Verslag. Kontrakt Sulthan En Pangeran Ratu Van Djambi van 2 November 1858

Azyumardi Azra, Jaringan Ulama Timur Tengah dan Kepulauan Nusantara Abad XVII dan XVIII: Melacak Akar-akar Pembaharuan Pemikiran Islam Di Indonesia. Bandung: Mizan, 1994.

Azyumardi Azra. Renaisans Islam Asia Tenggara: Sejarah, Wacana, dan Kekuasaan. Bandung: Rosda Karya, 1999.

Bernard H. M Vlekke. Nusantara: Sejarah Indonesia. (Jakarta: KPG, Freedom Institute dan Balai Pustaka, 2008.

Eddy Soetrisno dan Elizabeth Tara, MD. 100 Pabla wan Nasional dan Sejarah Perjuangannya. Jakarta: Ladang Pustaka \& Intimedia, 2001.

Elsbeth Locher-Scholten. Kesultanan Sumatra dan Negara Kolonial, bubungan Jambi-Batavia (18301907) dan Bangkitnya Imperialisme Belanda. Terjemahan; Noor Cholis. Jakarta: Banana, KITLV, 2008.
Irhash A Shamad. Ilmu Sejarah. Jakarta: Hayfa Press, 2004.

Junaidi T. Noor. Mencari Jejak Sangkala. Jambi: Pusat Kajian Pengembangan Sejarah dan Budaya Jambi, 2007.

Karel A. Steenbrink. Beberapa Aspek Tentang Islam Di Indonesia Abad Ke-19. Jakarta: Bulan bintang, 1984.

Komaruddin Hidayat dan Ahmad Gaus AF, (ed). Menjadi Indonesia: 13 Abad Eksistensi Islam Di Bumi Nusantara. Jakarta: Yayasan Festival Itiqlal dan Mizan, 2006.

Lindayanti, dkk. Jambi Dalam Sejarah 1500-1942. Jambi: Pusat Kajian Pengembangan Sejarah dan Budaya Jambi, 2013.

Mardanas Sofwan. Riwayat Hidup dan Perjuangan Sultan Thaha. Jakarta: Proyek Biografi Pahlawan Nasional Departemen Pendidikan dan Kebudayaan, 1976.

Mirnawati. Kumpulan Pahlawan Indonesia Terlengkap. Jakarta: CIF, 2012.

Masjkuri. Sultan Thaba Saifuddin. Jakarta: DEPDIKBUD Proyek Inventarisasi dan Dokumentasi Sejarah Nasional, 1985.

Muchtar Agus Cholif. Timbul Tenggelam Persatuan Wilayah Luak XVI Tukap Khunut di Bumi Undang Tambang Teliti. Jambi 1 Januari 2009. Robert Cribb and Audrey Kahin. Kamus Sejarah Indonesia. Jakarta Komunitas Bambu, 2012. 